\title{
Desafios para a prática docente no ambiente hospitalar: formação inicial em contexto ${ }^{1}$
}

\author{
Milene Bartolomei Silva ${ }^{2}$ \\ Aline Santa Cruz ${ }^{3}$ \\ Ordália Alves Almeida
}

\begin{abstract}
RESUMO
Trata-se de pesquisa realizada sobre atendimento pedagógico em Hospital Universitário de Campo Grande/MS, a qualidade da ação profissional dos que trabalhar nesse ambiente. Questionamos se o curso de Pedagogia é suficiente para a atuação no Ambiente Hospitalar e se os profissionais estão qualificados para desenvolver atividades pedagógicas. Objetivou-se refletir sobre o papel, as práticas pedagógicas e os desafios do professor para realizar o atendimento pedagógico no Ambiente Hospitalar e contribuir para a ampliação de reflexões sobre a atividade na Classe Hospitalar. A metodologia sustentou-se nas contribuições teóricas de Ceccim (1999), Fonseca (1999 e 2015), Matos (2014), entre outros, nas observações e entrevista semiestruturada com profissionais que atuam na área. O trabalho docente no contexto hospitalar é fundamental para as crianças hospitalizadas, oportunizando-lhes a continuidade da escolarização. Concluímos que a formação inicial é insuficiente para a atuação na classe hospitalar, levando os profissionais a buscarem cursos de capacitação e especializações.
\end{abstract}

PALAVRAS-CHAVE: Atendimento Pedagógico. Ambiente Hospitalar. Formação inicial. Práticas Pedagógicas.

\footnotetext{
${ }^{1}$ Apoio: Universiade Federal de Mato Grosso do Sul.

2 Doutora.Universidade Federal de Mato Grosso do Sul, Campo Grande, Mato Grosso do Sul, Brasil. Orcid: https://orcid.org/0000-0003-3765-3139. E-mail: milenebatsilva@gmail.com.

${ }_{3}$ Pedagoga. Universidade Federal de Mato Grosso do Sul, Campo Grande, Mato Grosso do Sul, Brasil. Orcid: https://orcid.org/0000-0001-6185-8826. E-mail: alinesantacruz@ hotmail.com.

${ }^{4}$ Pós-doutora. Universidade Federal de Mato Grosso do Sul, Campo Grande, Mato Grosso do Sul, Brasil. Orcid: https://orcid.org/0000-0002-5075-958X. E-mail: ordaliaalmeida@terra.com.br.
} 
Challenges for teaching practice in the hospital environment:

initial training in context

\begin{abstract}
It is a research carried out on pedagogical assistance in a University Hospital of Campo Grande / MS, the quality of the professional action of those who work in these environments. We question whether the Pedagogy course is sufficient to work in the Hospital Environment and whether the professionals are qualified to develop pedagogical activities. The objective was to reflect on the role, pedagogical practices and challenges of the teacher to carry out the pedagogical assistance in the Hospital Environment and contribute to the expansion of reflections on the activity in the Hospital Class. The methodology was supported by the theoretical contributions of Ceccim (1999), Fonseca (1999 and 2015), Matos (2014), among others, in the observations and semi-structured interview with professionals working in the area. Teaching work in the hospital context is fundamental for hospitalized children, giving them the opportunity to continue schooling. We conclude that initial training is insufficient to work in the hospital class, leading professionals to seek training and specialization courses.
\end{abstract}

KEYWORDS: Pedagogical Service. Hospital Environment. Initial formation. Pedagogical practices.

Desafíos para la práctica docente en el ambiente hospitalario: la formación inicial en el contexto

\title{
RESUMEN
}

Se trata de una investigación realizada sobre la asistencia pedagógica en un Hospital Universitario de Campo Grande / MS, la calidad de la actuación profesional de quienes laboran en estos entornos. Nos preguntamos si el curso de Pedagogía es suficiente para trabajar en el Ambiente Hospitalario y si los profesionales están capacitados para desarrollar actividades pedagógicas. El objetivo fue reflexionar sobre el rol, prácticas pedagógicas y desafíos del docente para llevar a cabo la asistencia pedagógica en el Ambiente Hospitalario y contribuir a la ampliación de reflexiones sobre la actividad en la Clase Hospitalaria. La metodología se apoyó en los aportes teóricos de Ceccim (1999), 
Fonseca (1999 y 2015), Matos (2014), entre otros, en las observaciones y entrevista semiestructurada con profesionales que trabajan en el área. La labor docente en el contexto hospitalario es fundamental para los niños hospitalizados, dándoles la oportunidad de seguir escolarizados. Concluimos que la formación inicial es insuficiente para trabajar en la clase hospitalaria, llevando a los profesionales a buscar cursos de formación y especialización.

PALABRAS CLAVE: Servicio Pedagógico. Entorno hospitalario. Formación inicial. Prácticas pedagógicas.

$$
* * *
$$

\section{Introdução}

A escola já não se constitui em único espaço para o desenvolvimento do trabalho docente, empresas, associações assistenciais, hospitais, entre outros, são locais que cada vez mais demandam espaços para o fazer pedagógico. Desse modo, a diversidade desses ambientes exige práticas pedagógicas que levem em conta as necessidades e especificidades do público neles encontrados.

$\mathrm{O}$ atendimento educacional em hospitais, objeto desta pesquisa, ocorre nas classes hospitalares e, dependendo das condições físicas do aluno/paciente, podem ocorrer também nos leitos.

Esse atendimento se caracteriza como uma modalidade de ensino que visa a continuidade do processo de aprendizagem de toda criança e adolescente que esteja em fase de escolarização e que, por motivo de doença encontra-se internada ou em tratamento de saúde, afastando-se assim da rotina escolar.

As legislações brasileiras amparam e legitimam o direito à educação de todas as crianças e de todos os adolescentes, inclusive aos que se encontram internados ou hospitalizados. Dentre elas, destacam-se:

- No artigo 205 da Constituição Federal de 1988;

- A Lei n. 8.069/1990 (Estatuto da Criança e do Adolescente); 
- Resolução n. 41/1995 (Conselho Nacional de Defesa dos Direitos da Criança e do Adolescente);

- Lei n. 9.394/1096 (Diretrizes e Bases da Educação);

- Resolução n.02/2001 - CNE/CEB (Diretrizes Nacionais para a Educação Especial na Educação Básica); e

- Documento intitulado Classe hospitalar e atendimento pedagógico domiciliar: estratégias e orientações, editado pelo MEC, em 2002.

Todas essas legislações garantem às crianças e aos adolescentes hospitalizados o direito à continuidade de sua escolarização e principalmente a interação com a educação, garantindo-lhes uma hospitalização em um lugar mais humano, com brincadeiras, com estudos e com laços de afeto, tornando esse espaço diverso, favorável e propício também à aprendizagem.

O Atendimento Pedagógico em Ambiente Hospitalar é compreendido como uma modalidade da educação especial, pois atende crianças e adolescentes com necessidades educativas especiais em condições e em limitações específicas de saúde (BRASIL, 2002), que em decorrência de internações e/ou tratamentos médicos são temporariamente impedidos de frequentar a escola regular. Portanto, neste tempo é considerada uma criança ou um adolescente com necessidades educacionais especiais.

Segundo Melo e Lima (2015), um dos desafios que se destaca à Pedagogia Hospitalar é a falta de profissionais qualificados para atuar na Classe Hospitalar. Pois, de acordo com o Ministério da Educação (BRASIL, 2002), o professor que trabalha neste âmbito deve ser capacitado para trabalhar com a diversidade humana, com diferentes vivências, para propor procedimentos didático-pedagógicos e práticas alternativas necessárias ao processo ensino e aprendizagem dos alunos hospitalizados e para planejar e desenvolver atividades estruturadas e flexíveis, respeitando o ritmo pessoal e o estado clínico do aluno.

Neste sentido, ao atender uma criança ou adolescente hospitalizado, a prática pedagógica deve diferir do cotidiano escolar, e para isso, é necessário 
que haja profissionais capacitados e preparados para atuarem neste campo. Assim, como condução metodológica, alguns questionamentos foram levantados: Será que o curso de formação inicial é suficiente para a formação do profissional que atua no Atendimento Pedagógico em Ambiente Hospitalar? Existem profissionais realmente qualificados e preparados para desenvolver atividades pedagógicas neste ambiente?

Em vista disso, torna-se indispensável um estudo que busque investigar esses profissionais, a fim de refletir sobre o papel e os desafios dos professores para desenvolver uma prática docente de qualidade na Classe Hospitalar; bem como, contribuir para que este assunto seja ampliado, tendo em vista que existem acadêmicos e profissionais de educação que ainda desconhecem o serviço do Atendimento Pedagógico em Ambiente Hospitalar.

Para isso, investigamos a formação e as práticas pedagógicas dos professores que atuam na Classe Hospitalar do Hospital Universitário Maria Aparecida Pedrossian - HUMAP, do município de Campo Grande, estado de Mato Grosso do Sul.

\section{Atendimento Pedagógico em Ambiente Hospitalar: um direito Pedagógico}

Diante da necessidade de oferecer a continuidade da escolarização às crianças e aos adolescentes hospitalizados e/ou que por algum motivo de doença, foram afastados do âmbito formal da escola, surge o Atendimento Pedagógico em Ambiente Hospitalar.

A criação de classes escolares em hospitais é resultado do reconhecimento formal de que crianças hospitalizadas, independentemente do período de permanência na instituição ou de outro fator qualquer, têm necessidades educativas e direitos de cidadania, onde se inclui a escolarização (AMARAL, 2015, p. 70).

Assim, a Classe Hospitalar foi criada com o objetivo de assegurar às crianças e aos adolescentes hospitalizados a continuidade dos conteúdos 
regulares de ensino, possibilitando um retorno à escola após a alta, sem prejuízos à sua formação escolar e buscando assim recuperar a socialização do aluno por um processo de inclusão, dando continuidade a sua aprendizagem.

Desse modo, o Atendimento Pedagógico em Ambiente Hospitalar tem a função de desenvolver uma singular atenção pedagógica às crianças e aos adolescentes escolares que se encontram em atendimento hospitalar, apresentando alternativas que contribuam para a aprendizagem e o bem-estar deles, pois é evidente a importância da continuidade de sua escolarização, para que não haja prejuízos em seu processo de aprendizagem e na sua formação escolar.

Segundo Fonseca (1999), a primeira Classe Hospitalar do Brasil surgiu em 1950, no Hospital Municipal Jesus, no município de Rio de Janeiro, funcionou sem apoio e vínculo nenhum com Estado e com a Secretaria de Educação e foi considerada em âmbito nacional como o marco da pedagogia hospitalar, Porém, neste período, os alunos que passassem por enfermidades que os obrigassem ao afastamento escolar, eram submetidos à continuidade do aprendizado sem as mínimas condições e oportunidade, resultando, muitas vezes, na reprovação, desistência, ou até algumas vezes em aprovações sem o necessário conhecimento, que seria exigido na série seguinte, prejudicando assim significativamente o processo de aprendizagem do aluno.

De acordo com Matos (2014), a segunda Classe Hospitalar surgiu no ano de 1960, também no município de Rio de Janeiro, mas, assim como a primeira Classe Hospitalar, essa também não tinha apoio e vínculo nenhum com Estado e com a Secretaria de Educação. Os profissionais na área da saúde observaram a necessidade cognitiva que as crianças internadas por longos tempos apresentavam e, então, começaram a realizar ações educativas por conta própria, contavam somente com o apoio das direções e equipe do hospital.

Desde então, o atendimento pedagógico que ocorre em ambientes de tratamento de saúde, vem ocorrendo graças a movimentos e lutas a favor do direito à educação das crianças e dos adolescentes hospitalizados. A partir 
de 1988 passa a fazer parte de um processo de redemocratização expressa na Constituição Federal, que dimensiona a educação como um direito de todos (BRASIL, 1988). Mas, ainda assim, foram necessários, muitos anos para que as autoridades constituídas para o exercício da educação fossem compelidas a aceitar e a normatizar a Classe Hospitalar.

Só na década de 1990 que, no Brasil, foram criadas leis especificas para a Classe Hospitalar, dentre elas o Estatuto da Criança e do Adolescente, em especial, o artigo nove, que trata do direito à educação: "Direito de desfrutar de alguma forma de recreação, programa de educação para a saúde" (grifo nosso) (BRASIL, 1990).

Em 1995, foi aprovada a lei dos Direitos das Crianças e Adolescentes Hospitalizados, através da Resolução n. 41 do CONANDA Conselho Nacional dos Direitos da Criança e do Adolescente e, assim, a ação educativa hospitalar ganha mais força e visibilidade, aparecendo no cenário nacional com status de legislação, dispondo que o aluno hospitalizado deve receber amparo psicológico, quando necessário, e deve desfrutar de alguma forma de recreação, de programas de educação para a saúde e de acompanhamento do currículo escolar, de acordo com a fase cognitiva, durante sua internação (BRASIL, 1995).

Em 1996, a classe hospitalar é inserida na LDB através da lei n. 9.394/1996 como educação especial, em uma visão de educação inclusiva, como uma modalidade da Educação Escolar, com recursos e procedimentos específicos para o processo de ensino e aprendizagem à disposição dos alunos com necessidades especiais, em respeito às suas diferenças, para que eles tenham acesso ao currículo e, consequentemente, conquistem sua integração social. Dispondo assim no seu artigo 58, parágrafo $2^{\circ}$ : "O atendimento educacional será feito em classes, escolas ou serviços especializados, sempre que, em função das condições específicas dos alunos, não for possível a sua integração nas classes comuns de ensino regular" (BRASIL, 1996).

Em 2001, o Conselho Nacional de Educação - CNE, tratou da obrigatoriedade de oferta das Classes Hospitalares, no artigo 13 da 
Resolução n. 02, indicando que os sistemas de ensino, mediante ação integrada com os sistemas de saúde, devem organizar o atendimento educacional especializado a alunos impossibilitados de frequentar as aulas, em razão de tratamento de saúde, que implique em internação hospitalar ou atendimento ambulatorial (BRASIL, 2001).

Em 2002, o MEC - Ministério da Educação publicou um documento com o título Classe Hospitalar e Atendimento Pedagógico Domiciliar: estratégias e orientações. Neste documento, encontram-se os princípios, os objetivos e as formas de organização e funcionamento administrativo e pedagógico das classes hospitalares e do atendimento pedagógico domiciliar (BRASIL, 2002). O referido documento tem como objetivo estimular a criação do atendimento pedagógico hospitalar e domiciliar, garantindo a educação aos alunos da escola regular que estejam hospitalizados assim designando:

Cumpre às classes hospitalares e ao atendimento pedagógico domiciliar elaborar estratégias e orientações para possibilitar o acompanhamento pedagógico-educacional do processo de desenvolvimento e construção do conhecimento de crianças, jovens e adultos matriculados ou não nos sistemas de ensino regular, no âmbito da educação básica e que se encontram impossibilitados de frequentar escola, temporária ou permanentemente e, garantir a manutenção do vínculo com as escolas por meio de um currículo flexibilizado e/ou adaptado, favorecendo seu ingresso, retorno ou adequada integração ao seu grupo escolar correspondente, como parte do direito de atenção integral (BRASIL, 2002, p. 13).

Entende-se, assim, classe hospitalar como o atendimento pedagógico educacional em ambientes de tratamento de saúde, às crianças e aos adolescentes em idade escolar que estejam hospitalizados, internados ou não e que estejam impossibilitadas de frequentar a escola. Neste sentido, a Classe Hospitalar vai muito além do que um simples espaço de sala de aula inserida no ambiente hospitalar. É uma modalidade de atendimento que faz parte da Educação Especial, pois trata de um atendimento pedagógico diferenciado, em que a atuação do educador deve tanto atender às 
necessidades educativas da criança ou do adolescente quanto respeitar o ritmo pessoal e o estado clínico do mesmo.

Uma pesquisa feita pelas autoras Ohara, Borba e Carneiro (2008), aponta em um levantamento realizado, em 2005, sobre o funcionamento de classes hospitalares no País, registrava que 99 hospitais haviam instalado as classes hospitalares, assim distribuídas por região: Região Norte= 7; Região Nordeste $=10$; Região Centro-oeste $=18$; Região Sudeste $=47$ e Região Sul $=17$.

Mais recentemente, em um estudo apresentado por Fonseca (2015), a autora contabiliza um total de 155 classes hospitalares em funcionamento no Brasil, sendo distribuídas da seguinte forma: Região Norte $=10 ;$ Região Nordeste $=26$; Região Centro-oeste $=26$; Região Sudeste $=64$ e Região Sul= 29. Quanto à matriculas em ambientes hospitalares, dados do Inep (Instituto Nacional de Estudos e Pesquisas Educacionais Anísio Teixeira) revelam uma evolução no país entre 2013 de $18 \%$ para $38,2 \%$ em 2017 , sendo que deste total, $25,2 \%$ de matriculas foram no Ensino Fundamental (Censo Escolar Mec, 2017).

A partir dessas pesquisas vimos que em nosso país houve um aumento significativo da criação de Classes Hospitalares, porém este número é ainda muito pequeno se considerarmos a imensidão do território brasileiro. O Atendimento Pedagógico em Ambiente Hospitalar deveria existir em todos os hospitais que atendem crianças e adolescente, pois, de acordo com as legislações vigentes, constitui-se em direito de todo estudante hospitalizado, impedido de frequentar a escola regular, e ainda, como citado anteriormente, a partir do ano de 2001, o Conselho Nacional de Educação (CNE) tornou obrigatório a oferta de Classe Hospitalar em hospitais que atendem crianças e adolescentes em idade escolar impossibilitadas de frequentar a escola em razão de tratamento de saúde que implique em internação hospitalar ou atendimento ambulatorial (BRASIL, 2001).

Tanto o atendimento educacional em ambiente hospitalar, quanto o atendimento pedagógico domiciliar devem estar vinculados aos sistemas 
de educação como uma unidade de trabalho pedagógico das Secretarias Estaduais, do Distrito Federal e Municipais de Educação, como também às direções clínicas dos sistemas e serviços de saúde em que se localizam (BRASIL, 2002). Um trabalho articulado para um atendimento de qualidade que proporcione a criança/adolescente hospitalizada menos possível de prejuízo ao seu processo de aprendizagem, possibilitando a igualdade de condições para o acesso ao conhecimento, assim como o acesso à escola e a permanência nela (BRASIL, 2002).

\section{A atuação do professor e sua prática pedagógica no Atendimento Pedagógico em Ambiente Hospitalar}

A atuação do professor e a sua prática pedagógica não se restringe apenas ao ambiente escolar, mas também em outros ambientes, como por exemplo em hospitais. Neste ambiente, o professor atua na Classe Hospitalar, com alunos temporariamente afastados da escola regular, em decorrência de internações e/ou tratamentos médicos e que se encontram em estado debilitado de saúde e com necessidades educativas especiais.

A atuação desse profissional e as mediações pedagógicas realizadas por ele, em especial no acompanhamento pedagógico de crianças e adolescentes em situação de internamento hospitalar ou tratamento de saúde difere-se da prática pedagógica realizada na escola. Neste sentido, Rodrigues (2012) nos alerta que no ambiente hospitalar,

[...] não podemos apenas utilizar das mesmas estratégias utilizadas em sala de aula regular, isso não é possível por suas peculiaridades, que exige do professor uma postura de trabalho flexível e que seja capaz de lidar diariamente com a diversidade, que seja capaz de avaliar em curto prazo, se o escolar naquele momento (independente de sua idade) apresenta condições físicas, psicologias para participar das atividades pedagógicas educacionais promovidas pelo professor, respeitando, assim, o tempo de aprendizagem de cada indivíduo (RODRIGUES, 2012, p. 88). 
Portanto, o aluno hospitalizado requer métodos de tratamento diferenciados da educação regular, fazendo com que o profissional da Educação que com ele trabalha leve em conta a sua hospitalização e atue de forma flexível de acordo com as suas necessidades e limitações.

Segundo Matos e Mugiatti (2009), o atendimento educacional no ambiente hospitalar requer, pela sua especificidade, habilitados e competentes profissionais, lançando, com isso, um verdadeiro desafio aos cursos de Pedagogia e demais licenciaturas, para fundamentar suas propostas curriculares a partir de pesquisas e práticas científicas multidisciplinares, interdisciplinares e transdisciplinares em contextos hospitalares.

Silva (2015, p.51), ressalta que "refletir sobre a atuação de pedagogos em hospitais tem sido uma questão bastante delicada na recente", e discutir sobre o mesmo, é um tanto quanto desafiante e divergente, visto a falta de uma formação inicial específica para o profissional atuar nesta área. Na perspectiva de Custódio (2017), para o que atendimento da Classe Hospitalar continue sendo efetivado e consequentemente traga bons resultados, é necessário que, durante a formação inicial, os profissionais tenham acesso aos conhecimentos inerentes ao atendimento educacional em ambiente hospitalar e a percebam como um campo possível e necessário de atuação.

A formação em Pedagogia Hospitalar faz-se, então, muito necessária para a atuação desse profissional, pois trata-se de profissionais que precisam estar preparados para exercer funções em um contexto diferenciado da escola. Num estudo feito por Barros (2007), a autora observa que a falta de uma formação que prepare esses profissionais para o ingresso no campo hospitalar, é uma questão negativa para a permanência e/ou desempenho satisfatório deles neste campo.

O documento intitulado Classe Hospitalar e atendimento pedagógico domiciliar (BRASIL, 2002), na tentativa de estruturar ações de organização do sistema de atendimento educacional fora do âmbito escolar propõe estratégias e orientações para o atendimento pedagógico e destaca que: 
O professor deverá ter a formação pedagógica preferencialmente em Educação Especial ou em cursos de Pedagogia ou licenciaturas, ter noções sobre as doenças e condições psicossociais vivenciadas pelos educandos e as características delas decorrentes, sejam do ponto de vista clínico, sejam do ponto de vista afetivo (BRASIL, 2002, p. 22).

Dessa forma, para desempenhar essa função, o professor precisa estar capacitado para lidar com as mudanças constantes nos planejamentos adequando-os a cada situação, e a cada aluno, levando em conta o momento afetivo, clínico e social que a criança ou adolescente se encontra, antes de insistir na realização de alguma tarefa. Com este intuito, é preciso ter criatividade e sensibilidade para enfrentar dificuldades e achar os meios necessários para superá-los.

Assim, a atuação e prática do professor no Atendimento Pedagógico em Ambiente Hospitalar estão relacionadas a uma visão humanística, que pensa no aluno/ paciente como um ser integral, com necessidades físicas, psíquicas e sociais, desse modo, o professor deve desenvolver um trabalho humanizado que atenda as dificuldades dessas crianças e desses adolescentes, oportunizando a realização do processo educativo e, acima de tudo, é preciso que o docente conheça a realidade do aluno, observe o seu desempenho e proponha atividades coerentes com o seu conhecimento, além de estimuladoras, propiciando assim uma aprendizagem significativa aos discentes internos.

Neste sentido, consequentemente é necessário que o professor do Atendimento Pedagógico em Ambiente Hospitalar seja submetido a uma capacitação e um preparo psicológico adequado, para realizar um trabalho pedagógico apropriado às condições peculiares de um aluno hospitalizado. Assim, é preciso que ele tenha acesso também a informações prévias em relação ao estado de saúde desse aluno, pois tais informações são considerações fundamentais que servirão de embasamento na elaboração do planejamento e na realização do seu atendimento. 


\section{Atendimento Pedagógico em Ambiente Hospitalar do Hospital Universitário Maria Aparecida Pedrossian}

O Hospital Universitário Maria Aparecida Pedrossian do município de Campo Grande, foi o pioneiro no atendimento de Classe Hospitalar, no estado de Mato Grosso do Sul, iniciando este atendimento por volta do ano de 1989. A princípio de maneira informal, com o intuito de amenizar o ócio e o sofrimento daqueles que ali ficavam internados.

No ano de 1994, um Grupo de Psicólogas e Psicopedagogas, vinculadas Secretaria de Estado de Educação - SED/MS, começaram a desenvolver um projeto de atendimento escolar, de forma direcionada. $\mathrm{O}$ atendimento era voltado para os alunos do Ensino Fundamental Anos Iniciais, $1^{\mathrm{a}}$ à $4^{\mathrm{a}}$ séries, com ênfase na alfabetização e a aprendizagem através de integração para inclusão. Em 1997, esse mesmo grupo de profissionais foi sendo complementado com a chegada de novos professores para o atendimento, que juntos passaram a atender o Ensino Fundamental Anos Iniciais e Anos Finais, $1^{\mathrm{a}}$ a $8^{\mathrm{a}}$ séries.

No ano de 2005, novamente, o grupo foi complementado, dessa vez com a chegada de professores de Química, Física e Biologia, para o atendimento do Ensino Médio. Hoje, o atendimento educacional no ambiente hospitalar ainda vinculada à Secretaria de Estado de Educação-SED/MS, tem seus professores lotados na Escola Estadual Vespasiano Martins, segue orientações pedagógicas do Centro Estadual de Educação Especial Inclusiva/ CEESPI e atende todas as crianças em idade escolar internadas em qualquer ala do Hospital, seja ela da educação infantil, ensino fundamental, ensino médio ou educação de jovens e adultos.

No Hospital Universitário Maria Aparecida Pedrossian, o atendimento da Classe Hospitalar não se restringe apenas aos estudantes da capital, mas a todos em idade escolar, independentemente de onde mora ou estuda, pois no hospital são internados indivíduos de todos os municípios do estado de Mato Grosso do Sul, inclusive de países vizinhos. 


\section{Aspectos metodológicos da pesquisa}

Este trabalho é resultado de uma pesquisa desenvolvida no Grupo de Estudos e Pesquisa sobre Educação e Desenvolvimento Humano GEPEDHI, da Universidade Federal de Mato Grosso do Sul. Foi desenvolvido por meio da metodologia qualitativa, fundamentada na abordagem sócio histórica. Bogdan e Biklen (1994, p. 11) afirmam que a investigação qualitativa surgiu de um campo inicialmente dominado por práticas de mensuração, de elaboração de testes de hipóteses variáveis, etc., campo a partir do qual "[...] alargou-se para contemplar uma metodologia de investigação que enfatiza a descrição, a indução, a teoria fundamentada e o estudo das percepções pessoais”.

\section{Participantes}

No trabalho de coleta de dados para esta pesquisa participaram integrantes do grupo de estudos e pesquisas GEPEDHI, juntamente com a orientação da professora coordenadora da pesquisa. E, como sujeitos da pesquisa, participaram 3 professoras e 1 coordenadora da Classe Hospitalar do Hospital Universitário Maria Aparecida Pedrossian - HUMAP, do município de Campo Grande, estado de Mato Grosso do Sul, com autorização do Comitê de ética da Plataforma Brasil sob o CAEE no 62205216.6.0000.0021, após a assinatura do Termo de Consentimento Livre e Esclarecido.

\section{Material}

O material utilizado para elaboração deste trabalho primeiramente foram artigos bibliográficos relacionados à linha de pesquisa: "Educação, Saúde e Práticas Pedagógicas", nos encontros no Grupo de Estudos e Pesquisa sobre Educação e Desenvolvimento Humano - GEPEDHI, o que perpassa pelas contribuições de vários autores, tais como: Ceccim (1999), Fonseca (1999 e 2015), Matos (2014), entre outros; o que de acordo com Prodanov e Freitas (2013) serviu, como primeiro passo, para sabermos em 
que estado se encontra o problema a que nos referimos; e posteriormente uma investigação de campo que teve início em outubro de 2017, realizada em lócus, juntamente com a orientação da professora coordenadora da pesquisa e colaboração de integrantes do grupo de estudos e pesquisas GEPEDHI, onde utilizou-se como material de pesquisa observações sistemáticas, entrevistas semiestruturadas constituídas com perguntas aos docentes que ali atuam e registros em "diários de bordo" (cadernos de anotações), que segundo Bogdan e Biklen (1994, p. 150) servem para "[...] relato escrito daquilo que o investigador ouve, vê, experiência e pensa no decurso da recolha de refletindo sobre os dados de um estudo qualitativo".

\section{Procedimento}

A investigação de campo, realizada em lócus, foi dividida em dois momentos. O primeiro momento realizado por 3 integrantes do grupo de estudos e pesquisa - GEPEDHI, de outubro a dezembro de 2017. E, o segundo momento, por outras 3 integrantes do mesmo grupo, nos meses de abril a novmebro de 2018. Todos os dados coletados, tanto no primeiro momento, quanto no segundo momento colaboram para a execução deste trabalho.

$1^{\circ}$ momento da investigação

No primeiro momento da investigação, apresentamos a proposta da pesquisa, o Termo de Consentimento Livre e Esclarecido (TCLE) e o roteiro (semiestruturado) de entrevista, elaborado por Custódio (2017), integrante do grupo de estudos e pesquisas- GEPEDHI, os quais foram compreendidos e aceitos prontamente pelas docentes.

Neste primeiro momento o intuito era de obter informações mais precisas acerca da formação e da prática pedagógica dos professores do Atendimento Pedagógico no ambiente Hospitalar do Hospital Universitário Maria Aparecida Pedrossian - HUMAP. As professoras serão aqui identificadas como Professora A, Professora B e Professora C, para terem sua identificação preservada. 
A partir dessa entrevista, observamos que as três eram graduadas em Pedagogia, duas delas trabalham na Classe desde 1995, cerca de 23 anos e possuem curso de especialização em Educação Especial. A outra há apenas quatro meses e está cursando, prestes a concluir também o curso de especialização em Educação Especial, estando assim de acordo com as orientações que o documento do MEC (2002) apresenta, "o professor deverá ter a formação pedagógica preferencialmente em Educação Especial ou em cursos de Pedagogia ou licenciaturas, ter noções sobre as doenças e condições psicossociais vivenciadas pelos educandos e as características delas decorrentes, sejam do ponto de vista clínico, sejam do ponto de vista afetivo" (BRASIL, 2002, p. 22).

Observamos também que além do curso de especialização em Educação Especial, as professoras em sua maioria buscam outros cursos específicos da área. Das 3 professoras entrevistadas 2 possuem o curso de especialização em Pedagogia Hospitalar. Porém, quando perguntamos se durante a graduação tiveram algum conhecimento teórico ou prático a respeito de Classe Hospitalar, e se esses conhecimentos foram suficientes para a atuação delas neste campo, todas responderam que em momento algum durante sua formação inicial, tiveram alguma informação a respeito de Classe Hospitalar.

Esses dados nos chamaram muita atenção, pois nos revelaram que o professor do Atendimento Pedagógico em Ambiente Hospitalar assume um grande desafio ao iniciar sua atuação neste ambiente, uma vez que é primordialmente com a sua prática que ele assume conhecimento e experiência para atuar neste campo, não havendo anteriormente nenhuma teoria que o levasse a compreender a sua prática. Sendo que ao nos apropriarmos de fundamentação teórica, nos beneficiamos de variados pontos de vista para uma tomada de decisão dentro de uma ação contextualizada, adquirindo perspectivas de julgamento para compreender e superar os diversos desafios que se apresentam no cotidiano desse ambiente. 
A partir desses dados, analisamos que as professoras se apropriam de conhecimento teórico e prático a respeito do Atendimento Pedagógico em Ambiente Hospitalar, quando já estão atuando nesse campo, a partir de suas vivências e experiências neste meio, de formações continuadas, de especializações e de cursos que tragam discussões a respeito da área.

Quando questionamos as professoras se elas tiveram alguma formação multidisciplinar para atuarem na Classe Hospitalar uma delas responde "No início não, mas depois tivemos cursos e, atualmente temos roda de conversas com a equipe multidisciplinar" (Professora B). Ainda, segundo as professoras, a SED/MS eventualmente oferece capacitações envolvendo sua área de atuação e as rodas de conversas que elas participam com a equipe contribui bastante para o desenvolvimento do trabalho delas.

No roteiro de entrevista, ainda foi questionado sobre a importância da atuação do professor dentro do hospital, e ao analisarmos as respostas vimos que as professoras consideram que a existência de classes hospitalares é de fundamental importância, pois elas oportunizam ao aluno hospitalizado a continuidade de seus estudos, evitando assim, prejuízos ao desenvolvimento de sua aprendizagem, consequentemente melhorando a sua autoestima. Segundo uma das entrevistadas, sua atuação é importante "para a continuação do desenvolvimento escolar do estudante que está hospitalizado, ajudando ele no que for necessário” (Professora C).

Questionamos, também, quanto a reação das crianças frente à presença e atuação do professor no hospital. As professoras destacaram que elas reagem entusiasmadas, sempre querem participar das aulas. Uma das professoras destacou que "a reações das crianças são muito boas, pois elas podem estudar mesmo estando em tratamento médico e a maioria delas fica entusiasmada e feliz" (Professora A).

Outra questão que pontuamos foi a respeito do planejamento das atividades. Perguntamos às professoras como funciona e como elas organizam os conteúdos, metodologias e avaliações. De acordo com as respostas, a organização do planejamento acontece semanalmente, seguindo 
sempre o referencial curricular vigente na Rede Estadual de Educação. E segundo as entrevistadas, as atividades que elas propõem sempre são flexíveis e adaptadas à realidade do aluno.

Cabe assim, citar Calegari-Falco (2007), que defende que,

Todo o atendimento da classe hospitalar deve ser flexível, de acordo com a condição e possibilidade da criança, levando em consideração o tempo de internação, estado psicológico, patológico e capacidade de mobilidade, estes deveram contribuir para que, mesmo quando hospitalizada, a criança mantenha o elo com o mundo que ficou fora do hospital, para assim participar e aprender desfrutando de seu direito básico ao desenvolvimento pleno, independente de suas dificuldades, mas direcionado para o seu potencial, reduzindo o tempo de internação de forma a resgatar a sua auto-estima, amenizando o sofrimento causado pela internação (CALEGARI-FALCO, 2007, p. 4287).

Concluímos assim, que as práticas pedagógicas das professoras são previamente e criteriosamente planejadas, de maneira que contribuam de maneira eficiente para o processo de aprendizagem do aluno.

Quanto aos recursos metodológicos que a professoras utilizam e consideram importantes para o processo de ensino aprendizagem das crianças, de acordo com as informações que obtivemos com o questionário, além das atividades flexíveis e adaptadas, são utilizados jogos pedagógicos, internet, livros didáticos e paradidáticos, computadores, vídeos, brinquedos, revistas, atividades impressas, entre outros.

$2^{\circ}$ momento da investigação

No segundo momento da investigação, nos meses de abril e maio de 2018, foi possível obter informações mais precisas acerca do funcionamento das Classes Hospitalares em Campo Grande/MS e especificamente a do Hospital Universitário Maria Aparecida Pedrossian, pois neste momento tivemos um contato maior com a coordenadora do Núcleo de Classe Hospitalar de Campo Grande/MS. 
De acordo com as informações obtidas da Coordenadora do Núcleo de Classe Hospitalar de Campo Grande/MS através das conversas dirigidas, há somente um núcleo de Classe Hospitalar em Campo Grande/MS. A equipe desse núcleo é composta por 19 profissionais, todos professores. Destes, atualmente, 6 atuam na Classe Hospitalar da pediatria do Hospital Universitário Maria Aparecida Pedrossian, sendo estes, 3 pedagogos e 3 professores de áreas distintas. Os demais trabalham nas outras instituições que também oferecem o atendimento de Classe Hospitalar: Hospital Regional, Hospital São Julião, Santa Casa e AACC (Associação dos Amigos das Crianças com Câncer). Porém, segundo a coordenadora, se houver maior demanda de atendimento em uma das instituições e em outra não, é realizado um remanejamento ou rodízio dos professores para o atendimento. Em cada uma dessas instituições há um professor responsável pela equipe que cumpre uma carga de $40 \mathrm{~h}$ semanais, os demais em sua maioria cumprem $20 \mathrm{~h}$ semanais.

De acordo com a coordenadora, o professor que atua no Atendimento Pedagógico em Ambiente Hospitalar é cedido pela SED/MS e desenvolve juntamente com a instituição de ensino a que o aluno esteja matriculado, todos os conteúdos curriculares, além de atividades artísticas, lúdicas e culturais. E os recurso para a realização dos atendimentos, tanto de materiais de consumo, como também de materiais permanentes, são fornecidos pela SED/MS e Hospital Universitário Maria Aparecida Pedrossian.

O horário de funcionamento da Classe Hospitalar da pediatria do Hospital Universitário Maria Aparecida Pedrossian ocorre no período matutino das $7 \mathrm{~h} 30$ às $11 \mathrm{~h} 30$. Porém, segundo a coordenadora, isso não significa que o aluno/paciente deva ficar durante todo o tempo de funcionamento na sala de aula estudando.

Ainda, segundo a coordenadora, o professor do Atendimento Pedagógico em Ambiente Hospitalar tem autonomia e responsabilidade de preparar as atividades para o aluno, a aula não tem que obrigatoriamente ter um registro no papel, pode ser oral, pode ser através de jogos de 
brincadeiras, desde que ofereça o conteúdo do período que o aluno está, e que procure sanar as dificuldades que ele apresenta.

Nesta fase de investigação, foi possível presenciarmos alguns atendimentos pedagógicos às crianças na Classe Hospitalar, e observamos que em todo momento a vontade do aluno é respeitada, ele só estuda se estiver em condições e se tiver vontade para isso, contudo os professores sempre orientam e o estimulam a participar. Eles têm sempre um contato afetivo e uma interação prazerosa com os alunos.

Em alguns momentos tivemos contato com crianças nos leitos hospitalares e foi possível observar que elas possuem os registros de suas atividades. Uma das crianças que observamos foi uma menina em idade pré-escolar; sua acompanhante nos informou que ela se encontrava há 17 dias hospitalizada, e que ali recebia atendimento escolar, o que considerava muito bom e significativo para a criança na superação das tristezas, das dores e do sofrimento causados pela enfermidade, mostrounos um envelope com várias atividades feitas pela paciente com auxílio das professoras do Atendimento Pedagógico em Ambiente Hospitalar. Enquanto conversávamos com a menina logo se enturmou e fez questão de nos mostrar atividade por atividade demonstrando bastante interesse e entusiasmo no desenvolvimento dos exercícios.

Isso nos faz refletir sobre o que Ceccim (1999) diz sobre a função do Atendimento Pedagógico em Ambiente Hospitalar,

[...] a função do professor de classe hospitalar não é a de apenas "ocupar criativamente" o tempo da criança para que ela possa "expressar e elaborar" os sentimentos trazidos pelo adoecimento e hospitalização, aprendendo novas condutas emocionais, como também não é a de apenas abrir espaços lúdicos com ênfase no saber pedagógico para que a criança "esqueça por alguns momentos" que está doente em um hospital. O professor deve estar no hospital para operar com processos cognitivos afetivos de construção da aprendizagem cognitiva e permitir aquisições escolares às crianças [...] (CECCIM, 1999, p. 03).

Nesse sentido a Classe Hospitalar oportuniza ao paciente uma hospitalização em um lugar mais humano, favorável e propício à 
aprendizagem. E o professor é o principal condutor desse espaço, responsável pelo contato com a criança e com o adolescente, pelo estimulo, pelo afeto, pelo aprendizado e consequentemente é responsável também pela melhora da saúde física e emocional desse aluno/paciente, pois o seu atendimento pedagógico, influencia e muito na recuperação de saúde do aluno hospitalizado.

\section{Considerações finais}

Esta pesquisa possibilitou compreender que o trabalho docente no contexto hospitalar é fundamental para o desenvolvimento da criança e do adolescente hospitalizado, oportunizando a estes continuidade de sua escolarização, oferecendo-lhes um atendimento mais humano e garantindo que o processo de aprendizagem, tão importante para nossa vida, não se exclua no contexto hospitalar.

Vimos que esse trabalho em ambientes hospitalares é um atendimento que já possui amparos legais, através de legislações que legitimam o direito à educação de todas as crianças e de todos os adolescentes, inclusive os que se encontram hospitalizados.

A rotina de uma criança ou adolescente durante um período de internação, certamente muda, e com certeza não é uma das mudanças mais confortáveis e prazerosas na vida destes indivíduos, visto que há um afastamento do seu lar, do seu convívio familiar, da escola, dos amigos. Nesse sentido o Atendimento Pedagógico em Ambiente Hospitalar tem a função de suprir um pouco dessa carência que os afeta, e ainda, beneficiar diretamente a questão intelectual durante a hospitalização, proporcionando a construção ininterrupta de seu aprendizado.

Com as respostas que obtivemos na entrevista que realizamos com as professoras, concluímos que apenas a formação inicial não é suficiente para a formação do profissional que atua na classe hospitalar, tanto que elas buscam cursos de capacitação e especializações na área, e uma das exigências mínimas para elas atuarem no campo é o curso de especialização em Educação Especial. 
Ou seja, para um atendimento de qualidade, as professoras precisam buscar uma preparação que não foi disponibilizada na sua formação inicial.

Contudo, observamos que existem profissionais qualificados e preparados para atuar no Atendimento Pedagógico em Ambiente Hospitalar, prova disso são as Professoras da Classe Hospitalar do Hospital Universitário Maria Aparecida Pedrossian, de Campo Grande/MS. Destacamos, porém que estas são qualificadas e preparadas porque buscaram e seguiram estudando após sua formação inicial.

Nesse sentido, essa pesquisa contribuiu não apenas para compreendermos o papel do professor da Classe Hospitalar, mas também refletirmos sobre a importância de um aprofundamento de estudos e pesquisas acerca da Classe Hospitalar nas estruturas curriculares das universidades, pois este é um dos possíveis e importantes campo de atuação docente. E, o professor é um elemento fundamental na busca de qualidade do ensino. Contudo, faz-se necessário que seja um profissional com formação qualificada e que compreenda criticamente seu papel no contexto educacional; contexto este que como mostrou-nos este estudo, pode estar inserido em diversificados ambientes, inclusive em instituições hospitalares.

Um dos elementos que contribui fortemente para uma prática de qualidade é o conhecimento teórico, pois como dito anteriormente, quando nos apropriarmos de fundamentação teórica nos beneficiamos de variados pontos de vista para uma tomada de decisão dentro de uma ação contextualizada, adquirindo perspectivas de julgamento para compreender os diversos contextos do cotidiano. Assim, é necessário que os futuros profissionais do Atendimento Pedagógico em Ambiente Hospitalar tenham acesso aos embasamentos teóricos à Classe Hospitalar desde sua formação inicial, pois o contexto hospitalar pressupõe profissionais capacitados e que compreendam as peculiaridades desse ambiente. Neste sentido, as universidades formadoras de professores devem se preparar para capacitar os profissionais para um cenário mais abrangente, pois a atuação do professor não tem ocorrido apenas no âmbito escolar, ela se estende para além da escola. 
Assim, este trabalho nos permitiu refletir sobre como o profissional de educação, "formado", "apto" a atuar na sua área de formação "encara" atuar na Classe Hospitalar: Como um desafio!

\section{Referências}

AMARAL, D. PATTI. Classes hospitalares no município do Rio de Janeiro: as vozes das professoras. Revista Educação e Políticas em Debate. V.4, n.1. RJ, 2015.

BARROS, A. S. S. Contribuições da Educação Profissional em Saúde à Formação para o Trabalho em Classes Hospitalares. Caderno Cedes. Campinas. Vol.27, n.73, p.257-278, set./dez. 2007.

BRASIL. Conselho Nacional dos Direitos da Criança e do Adolescente. Diretos da criança e do adolescente hospitalizados. Resolução $n$. 41, de 13/10/1995. Brasília/DF: Imprensa Oficial. 1995.

BRASIL. Constituição (1988). Constituição da República Federativa do Brasil. Brasília, DF: Senado, 1988.

BRASIL. Diretrizes e Bases da Educação Nacional. Lei n. 9394, de 20 de dezembro de 1996, Brasília/ DF: Imprensa Oficial. 1996.

BRASIL. Diretrizes Nacionais para Educação Especial na Educação Básica. Conselho Nacional de Educação. Brasília: MEC, 2001.

BRASIL. Estatuto das Crianças e do Adolescente. Lei n. 8.069, de 13 de jul.1990.

BRASIL. Ministério da Educação. Classe Hospitalar e atendimento pedagógico domiciliar: estratégias e orientações. Secretaria de Educação Especial. Brasília: MEC; SEESP, 2002.

BOGDAN, Roberto C.; BIKLEN, Sari Knopp. Investigação qualitativa em educação. Tradução Maria João Alvarez, Sara Bahia dos Santos e Telmo Mourinho Baptista. Porto: Porto Editora, 1994.

CALEGARI-FALCO, A. M. Classe hospitalar: a criança no centro do processo educativo. Anais do Educere, Curitiba, PUC, 2007

CECCIM, R. B. Classe hospitalar: encontros da educação e da saúde no ambiente hospitalar. Pátio Revista Pedagógica, 3 (10), 41- 44, 1999. 
CUSTÓDIO, T. P. Classe Hospitalar: Práticas pedagógicas desenvolvidas com crianças dos anos iniciais do ensino fundamental. Trabalho de conclusão de curso (Curso de Pedagogia) - Universidade Federal de Mato Grosso do Sul, Campo Grande, 2017.

FONSECA, E. S. A situação brasileira do atendimento pedagógicoeducacional hospitalar. Educação e Pesquisa, São Paulo, v. 25, n. 1, p. 117129, jan./jun. 1999.

FONSECA, E. S. Classe hospitalar e atendimento escolar domiciliar: direito de crianças e adolescentes doentes. Revista Educação e Políticas em Debate. v.4, n.1, jan./jul. 2015.

MATOS, E. L. M. Escolarização Hospitalar - Educação e saúde de mãos dadas para humanizar. 4.ed. Petrópolis, RJ: Vozes, 2014.

MATOS, E. L. M.; MUGIATTI, M. M. T. F. Pedagogia Hospitalar: $a$ humanização integrando educação e saúde. 7. ed. Petrópolis, RJ: Vozes, 2009.

MELO, D. C. Q; LIMA, V. M. M. Professor na Pedagogia Hospitalar: Atuação e Desafios. Colloquium Humanarum. Presidente Prudente. v.12, n.2, p. 144-152, abr./jun. 2015.

OHARA, V.; BORBA, R. I. H.; CARNEIRO, I. A. Classe Hospitalar: Direito da criança ou dever da instituição? Revista Social de Enfermeiros Pediatras. v.8, n.2, p. 91-99, dez. 2008.

PRODANOV, Cleber Cristiano; FREITAS, Ernani Cesar. Metodologia do trabalho Científico: Métodos e Técnicas da Pesquisa e do Trabalho Acadêmico. Edição digital. Novo Hamburgo: Feevale, 2013.

RODRIGUES, Karina Gomes. Pedagogia Hospitalar: A formação do professor para atuar em contexto hospitalar. 2012. 125 f. Dissertação (Mestrado em Educação) - Pontifícia Universidade Católica do Paraná, Curitiba, 2012.

SILVA, M. B. Trilhas pedagógicas articulam saúde e educação no desenvolvimento cognitivo infantil: criança com câncer. Tese (Doutorado) Programa em Saúde e Desenvolvimento da Região Centro Oeste. Universidade Federal de Mato Grosso do Sul. Campo Grande, MS: UFMS, 2015. 